\title{
The mathematical principles and design of the NAIS - a spectrometer for the measurement of cluster ion and nanometer aerosol size distributions
}

\author{
S. Mirme and A. Mirme \\ Institute of Physics, University of Tartu, Ülikooli 18, 50090 Tartu, Estonia \\ Correspondence to: S. Mirme (sander.mirme@ut.ee)
}

Received: 30 May 2011 - Published in Atmos. Meas. Tech. Discuss.: 13 December 2011

Revised: 27 February 2013 - Accepted: 7 April 2013 - Published: 29 April 2013

\begin{abstract}
The paper describes the Neutral cluster and Air Ion Spectrometer (NAIS) - a multichannel aerosol instrument capable of measuring the distribution of ions (charged particles and cluster ions) of both polarities in the electric mobility range from 3.2 to $0.0013 \mathrm{~cm}^{2} \mathrm{~V}^{-1} \mathrm{~s}^{-1}$ and the distribution of aerosol particles in the size range from 2.0 to $40 \mathrm{~nm}$. We introduce the principles of design, data processing and spectrum deconvolution of the instrument.
\end{abstract}

\section{Introduction}

Formation of aerosol by nucleation of particles and their subsequent growth has been observed in the atmosphere almost everywhere around the world (Kulmala et al., 2004). The formed particles, initially of nanometer size, may grow further, participate in cloud formation and influence the radiation balance and ultimately the climate. On local scales, these particles may be deleterious to atmospheric visibility and to human health.

Despite the growing interest, the driving factors of the phenomenon are still poorly studied (Kulmala et al., 2007b). One reason for this is the difficulty of measuring aerosol particles in the size range of a few nanometers under atmospheric conditions.

A number of aerosol instruments can sense fine nanometer-range particles and measure their concentration in the atmosphere using the principle of condensational growth and optical counting, but information about particle size variations is practically lost. Some information about particle size can be acquired by combining the readings of several counters with different cutoff sizes (Kulmala et al., 2007a) or by analyzing the pulse height of the instrument response (Marti et al., 1996). These methods exhibit some dependence on particle chemical composition.

The particle distribution in a broad particle size range is measured by spectrometers that use electrical mobility classification (e.g., SMPS, FMPS; Scanning/Fast Mobility Particle Sizer). The smallest mobility equivalent particle size that can be measured by these instruments is typically $3 \mathrm{~nm}$. It is often limited by the condensation particle counter (CPC) used for particle detection although there are recent advancements in this area. (Vanhanen et al., 2011; Lehtipalo et al., 2009; Jiang et al., 2011a,b; Kulmala et al., 2012). It has been shown that the disagreement between standard mobility spectrometers below $20 \mathrm{~nm}$ is significant (Wiedensohler et al., 2012).

Distributions of particles with sizes below $3 \mathrm{~nm}$ can be measured by some instruments that sense air ions (particles with an electric charge), e.g., the AIS (Air Ion Spectrometer Mirme et al., 2007), BSMA (Balanced Scanning Mobility Analyzer; Tammet, 2006). As these instruments do not sense uncharged particles, a big fraction of aerosol is left unmeasured.

\section{The principle}

An electrical aerosol instrument assesses the total concentration of particles (including the uncharged fraction) based on a known probability distribution of electric charge on a particle after the aerosol has been charged in well-defined conditions. The particles are detected electrically by their carried electric charge. Thus, the limitation of the CPC principle is avoided. 
Also, the method is not sensitive to the chemical composition of particles. Only large, purely dielectric nonconductive particles $(d>500 \mathrm{~nm})$ are detected incorrectly, because they obtain less electric charge, but those are unlikely to occur in the normal atmosphere.

A common way to charge particles is to pass the aerosol through an aerosol neutralizer right before the measurement unit. The obtained charge is strongly dependent on particle size. For smaller particles the charging probability decreases and particle loss increases, which causes the electric response signal to gradually drop. Thus, the lower limit of the measurable particle size range is primarily determined by measurement uncertainties.

Here we introduce the Neutral cluster and Air Ion Spectrometer (NAIS, developed by Airel Ltd., Estonia) that uses the principle of electrical aerosol spectrometry. The NAIS has been specifically designed for monitoring of atmospheric nanometer aerosol. It can operate for long periods in a wide range of ambient conditions, from polluted downtown to remote forest, measuring the size distributions of naturally charged particles (ions) of both polarities as well as uncharged particles. It is based on the Air Ion Spectrometer (AIS, Mirme et al., 2007).

Like the AIS, the NAIS consists of two multichannel electrical mobility analyzer columns operating in parallel. The columns differ by the polarity of the ions measured, but are otherwise identical (Fig. 1). The aerosol is simultaneously mobility classified in the mobility analyzers and measured with an array of 21 electrometers per column.

Both columns have a software controlled sample preconditioning unit in front of the analyzers, which allows the instrument to switch between either detecting naturallycharged particles (ions) or all particles (including the uncharged fraction) by using unipolar charging. The mobility range in ions mode is from 3.2 to $0.0013 \mathrm{~cm}^{2} \mathrm{~V}^{-1} \mathrm{~s}^{-1}$. This covers both the cluster ions ranging (at $20^{\circ} \mathrm{C}$ ) from 3.2 to $0.5 \mathrm{~cm}^{2} \mathrm{~V}^{-1} \mathrm{~s}^{-1}$ and the aerosol ions ranging from 0.4 to $0.0013 \mathrm{~cm}^{2} \mathrm{~V}^{-1} \mathrm{~s}^{-1}$ (Hõrrak et al., 2000). The size range in particles mode is from below $2 \mathrm{~nm}$ up to $40 \mathrm{~nm}$ given in Stokes-Millikan mobility equivalent diameter at NTP (normal temperature and pressure) conditions.

The two similar measurement columns with opposite polarity operating in parallel allow the NAIS to detect variations of natural electric charge balance in the atmosphere and possible effects of electric charge polarity on charging of nanometer-size aerosol.

\section{Methods}

There are more than 15 NAIS instruments in use today. The technology has been developed gradually and implemented into new instruments along the way. The first five instruments built were very similar to the AIS, only with added particle charging. We describe the second generation NAIS, which

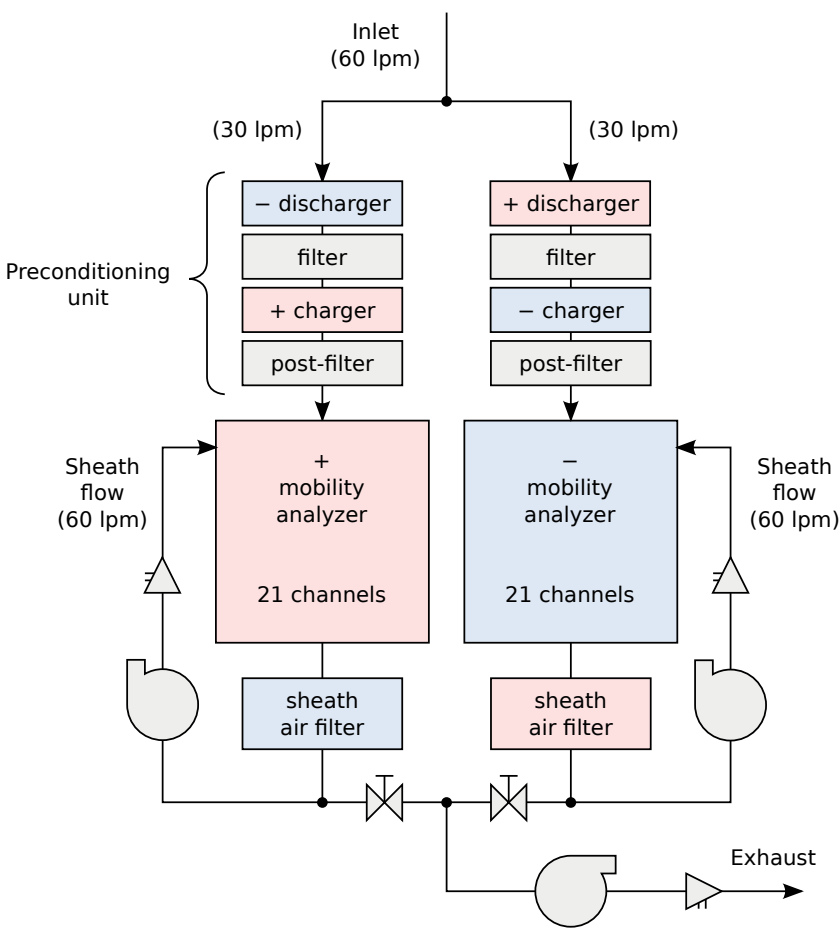

Fig. 1. NAIS measurement flow process.

has an updated airflow system and much enhanced data acquisition. Most of the information presented here is valid for the older instruments as well.

\subsection{Sample preconditioning}

The sample preconditioning unit consists of a discharger, an electric filter, a charger and another electric filter (called the postfilter). The charger and postfilter correspond to the electrical measurement principle (Flagan, 1998), where the instrument consists of aerosol charging followed by mobility analysis and data acquisition.

In ion mode, all components of the preconditioning unit are switched off, so the aerosol sample is left unmodified and only naturally-charged particles are sensed by the electric mobility analyzer. In this case the NAIS operates just like the AIS.

In particle mode, the main charger is switched on and the instrument detects all particles. The postfilter is used to remove the excess of charger ions. In this operating mode, the NAIS is similar to the Electrical Aerosol Spectrometer (EAS, Tammet et al., 2002).

To improve the instrument performance when measuring aerosol with non-steady state charge distribution, the discharger may be switched on (alternating charging mode). This provides some neutralization of the aerosol sample and thus reduces the effect of the particle's initial charge on the measurement result. 


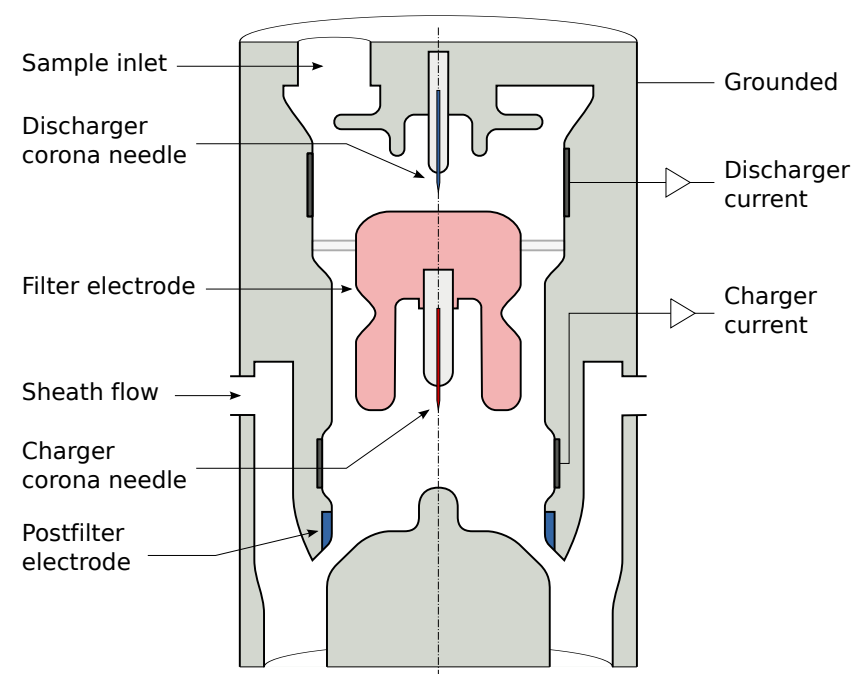

Fig. 2. Schematic of NAIS charger.

When only the discharger and the adjacent filter are switched on, then no detectable particles can enter the analyzer. This is called the offset mode and it is used to periodically verify the instrument operation (e.g., evaluate noise levels and measure parasitic currents).

\subsection{Charging}

To assess the aerosol particle size distribution, it is necessary to know the charge distribution of particles exiting the charger as a function of charging conditions and particle size.

The NAIS uses unipolar corona chargers - essentially a corona needle on the axis of a cylindrical volume (Fig. 2). The ions from the tip of the needle travel across the aerosol sample flow and attach to particles mainly by thermal diffusion. The charging ion concentration is maintained at a constant level by stabilizing the current that reaches the electrode surrounding the charging space.

The process of a particle acquiring electric charge is viewed as a flux of ions onto the particle. The flux is calculated using the kinetic theory (Podolsky, 1977) inside the limiting sphere around a particle (Fuchs, 1963). The radius of the limiting sphere is a parameter specified at the calibration.

The probability distribution of electric charge on particles after passing the charger is calculated by integrating a birth-death differential equation (Boisdron and Brock, 1970) considering the charger characteristics. An integral formula (Salm, 1992) is used to produce the complete distribution. The formula allows calculation of the charger's output charge distribution for an arbitrary initial charge distribution (e.g., a bipolar equilibrium charging state). A typical result for the NAIS charger is presented in Fig. 3.

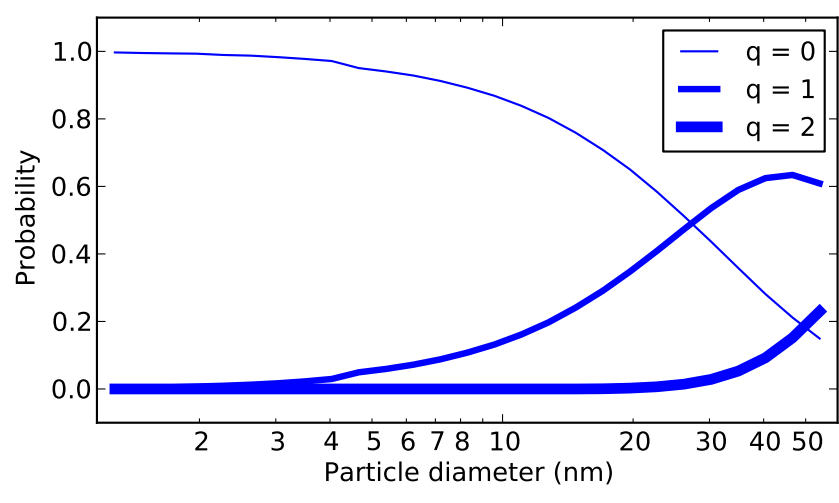

Fig. 3. The probability of particles having 0,1 or 2 elementary charges after passing the main charger of the NAIS.

The charger is characterized with the charging parameter $\alpha$ (Tammet, 1992):

$\alpha=\frac{1}{\varepsilon_{0}} \int \sigma \mathrm{d} t$,

where $\varepsilon_{0}$ is the vacuum permittivity and $\sigma=e z_{i} n$ is the electrical conductivity of air ( $e$ is the elementary charge, $z_{i}$ is the electrical mobility of charging ions, and $n$ the ion concentration). The exact value of the charging parameter is determined at the calibration. The difference between positive and negative charging efficiency is insignificant compared to the uncertainty level of the measurements.

The ions generated by the corona discharge are in the same mobility range as ions measured by the first channels of the analyzer. The postfilter removes most of the charger ions to avoid saturating the electrometers with too much current. Only particles larger than the charger ions can reliably be measured. The lower size limit of NAIS in particle mode is thus $\sim 2 \mathrm{~nm}$ (Asmi et al., 2009; Manninen et al., 2011).

The design of the discharger is similar to that of the subsequent main charger but it works in the opposite electrical polarity. In offset mode, when only the discharger is switched on, particles are charged to the wrong polarity for the respective analyzer, so the measured signal only consists of the parasitic (offset) currents and measurement noise. By knowing the offset signal, measurement uncertainties can be significantly decreased and reliability of the results improved.

When the instrument operates in the particles measurement mode, the enabling of the discharger in addition to the main charger can provide neutralization of particles as initially charged particles are effectively discharged with opposite-polarity charger ions either in the discharger or main charger, depending on their initial charge.

\subsection{Mobility analysis}

The measurement process that follows the preconditioning is again similar to that of AIS. The only addition is that, in particles measurement mode, the probability distribution of 


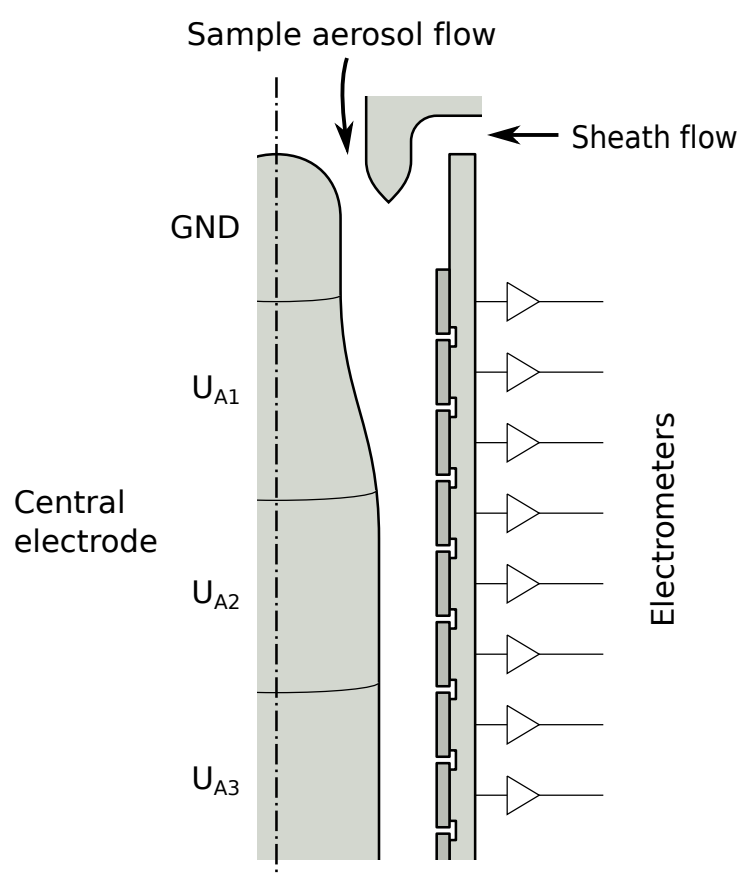

Fig. 4. Schematic of NAIS mobility analyzer.

electric charge on particles must be taken into account to calculate the size distribution.

The mobility analyzer consists of a number of cylindrical electrodes (Fig. 4). The central electrode is divided into several sections, each biased at a different fixed electric potential. The charge-collecting outer electrodes are connected to electrometric amplifiers at near ground potential, which in turn are connected to a data acquisition system. The charged aerosol is sucked into a circular slit near the central electrode. The clean sheath air is introduced near the outer electrode. The particles travel along the analyzer, and those with the same charge electrical polarity as the central electrode are pushed towards the outer electrodes by a radial electric field. The particles that have been deposited on a collecting section pass their charge on to the respective amplifier.

The mobility analysis follows the generic aspiration theory (Tammet, 1970). According to the theory, the movement of a charged particle with the electrical mobility $z$ in an analyzer is determined by the airflow rate $\Phi$ and the electric field (C. $U$ product) that is crossed by the particle while traveling inside the analyzer:

$z=\frac{\Phi \cdot \varepsilon_{0}}{C \cdot U}$

The formula determines the relationship between three parameters: airflow rate, mobility and analyzer capacitance. Fixing one of them fixes the ratio of the other two. So an ion with the mobility $z$ attaching to an outer electrode has passed the flow rate $\Phi$ and the electric field $C U$. This allows calculation of the attachment locations of ions with different
Table 1. The electrical capacitance (in $\mathrm{pF}$ ) between collecting sections and the four central sections of the NAIS mobility analyzer.

\begin{tabular}{lrrrr}
\hline \multirow{2}{*}{ Collecting } & \multicolumn{4}{c}{ Central section $\left(U_{\mathrm{A}}\right)$} \\
\cline { 2 - 5 } section & $9 \mathrm{~V}$ & $25 \mathrm{~V}$ & $220 \mathrm{~V}$ & $800 \mathrm{~V}$ \\
\hline 0 & 3030 & 0 & 0 & 0 \\
1 & 2531 & 0 & 0 & 0 \\
2 & 2433 & 0 & 0 & 0 \\
3 & 2504 & 0 & 0 & 0 \\
4 & 2913 & 0 & 0 & 0 \\
5 & 3860 & 0 & 0 & 0 \\
6 & 5597 & 0 & 0 & 0 \\
7 & 8250 & 0 & 0 & 0 \\
8 & 8716 & 0 & 0 & 0 \\
9 & 4006 & 4526 & 0 & 0 \\
10 & 0 & 8693 & 0 & 0 \\
11 & 0 & 8741 & 0 & 0 \\
12 & 0 & 9850 & 0 & 0 \\
13 & 0 & 5850 & 5235 & 0 \\
14 & 0 & 0 & 10656 & 0 \\
15 & 0 & 0 & 11149 & 0 \\
16 & 0 & 0 & 13558 & 0 \\
17 & 0 & 0 & 11784 & 8061 \\
18 & 0 & 0 & 0 & 19053 \\
19 & 0 & 0 & 0 & 25330 \\
20 & 0 & 0 & 0 & 25472 \\
21 & 0 & 0 & 0 & 25510 \\
\hline & & & &
\end{tabular}

mobilities entering the analyzer at different flow rates. The formula can be modified for the analyzer, consisting of multiple sections as follows:

$z_{n}=\frac{\left(\Phi_{\mathrm{a}}+\Phi_{\mathrm{s}}\right) \cdot \varepsilon_{0}}{\sum_{i=0}^{n} C_{i} \cdot U_{i}}$

where $\Phi_{\mathrm{a}}$ is the sample aerosol flow rate, $\Phi_{\mathrm{s}}$ is the sheath flow rate, and $z_{n}$ is the lowest (limiting) mobility of particles reaching the the section $n$.

The capacitances between the collecting sections and sections of central electrodes for the NAIS are presented in Table 1 . The table also shows the voltages of the respective sections. Note that the collecting sections are not matched with the central sections: collecting sections 9,13 and 17 have some capacitance with two adjacent central sections. This is used to cover a wide mobility range quite smoothly with a limited number of central sections. The calculated theoretical responses (transfer functions) for each section of the mobility analyzer are quite broad (Fig. 5) and have a varying mobility resolution. These transfer functions are typical for DMA (differential mobility analyzer) type instruments - their shape is determined by the relation between sheath and sample flow speeds. 


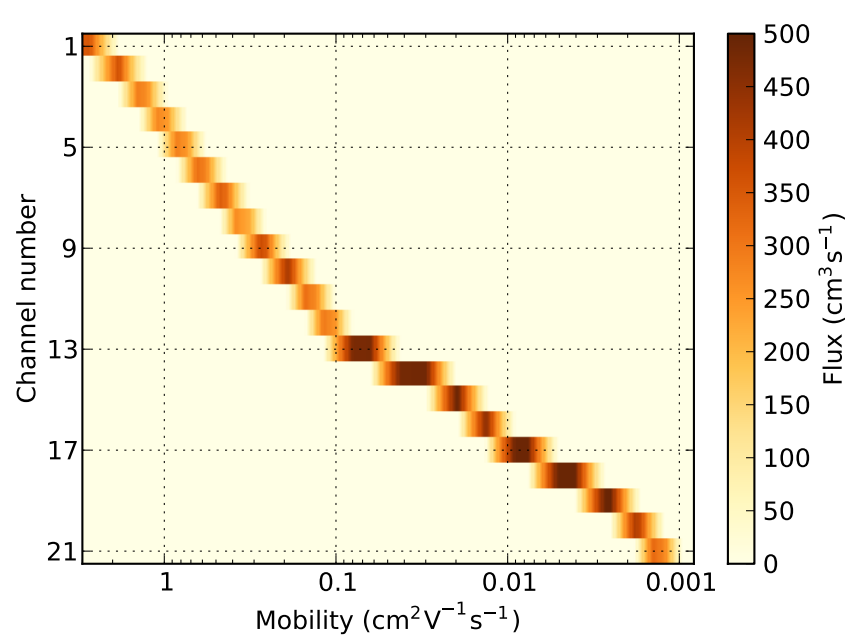

Fig. 5. Analyzer response $G(i, z)$ for the NAIS. It can be seen that the responses for individual channels are overlapping.

\subsection{Relationship between particle size and electrical mobility}

Once particles are charged, their electrical mobility distribution can be measured with a mobility analyzer. In order to proceed from that to particle size distribution, the particle mobility must be related to the particle size and electric charge.

NAIS uses the well-known and generally accepted Millikan formula (Fuchs, 1964):

$z_{\text {Millikan }}=e \frac{1+\frac{\lambda}{r}\left[a+b \exp \left(-c \frac{r}{\lambda}\right)\right]}{6 \pi \eta r}$,

where $a, b$ and $c$ are empirical constants, $e$ is the elementary charge, $\lambda$ is the particle mean free path, and $\eta$ is the viscosity of air. The mobility of a particle of a given size is a function of ambient atmospheric pressure and temperature.

The correction by Tammet (Tammet, 1995) may be used to improve the relation for the smallest particles. Particles smaller than $2 \mathrm{~nm}$ are not reliably measured by the instrument due to charger ion effects in any case. Experiments have shown that the presently used formula works well above that size. However, it has been made so that it is easy to recalculate the results if better size-mobility relations become known.

Newer generation NAIS instruments automatically adjust their sample and sheath airflow speeds so that the particle sizing and sample volume flow rate remain constant regardless of air pressure.

Under NTP conditions, the NAIS uses the sheath flow value $\Phi_{\mathrm{s}}=1000 \mathrm{~cm}^{3} \mathrm{~s}^{-1}$ and the sample flow value $\Phi_{\mathrm{a}}=500 \mathrm{~cm}^{3} \mathrm{~s}^{-1}$. If we consider Eq. (2), the size of the classified particle remains invariant of air pressure if $\Phi_{\mathrm{s}}$ and $\Phi_{\mathrm{a}}$ are chosen so that the expression $\frac{\Phi_{\mathrm{s}}+\Phi_{\mathrm{a}}}{z}$ remains invariant of air pressure.
In case of small particles, for which the mean free path is much larger than particle radius, Eq. (4) can be simplified (Tammet, 1995). After substituting $\lambda$ and $\eta$, we get the Eq. (5):

$\lim _{r \rightarrow 0} z_{\text {Millikan }}=\frac{e(a+b)}{6 \pi r^{2}} \frac{1.256}{P} \sqrt{\frac{k T}{m_{g}}} \propto \frac{\sqrt{T}}{P}$,

where $m_{g}$ is the mass of air molecule, $P$ is air pressure and $T$ is temperature.

In NAIS, the sample flow rate $\Phi_{\mathrm{a}}$ is kept constant. Considering Eqs. (2) and (5), this means that the size classification remains air pressure invariant if $\Phi_{\mathrm{S}}$ is chosen, so that the following relation holds:

$\left(\Phi_{\mathrm{s}}^{\prime}+\Phi_{\mathrm{a}}^{\prime}\right) \frac{\sqrt{T^{\prime}}}{P^{\prime}}=\left(\Phi_{\mathrm{s}}+\Phi_{\mathrm{a}}^{\prime}\right) \frac{\sqrt{T}}{P}$,

where $\Phi_{\mathrm{s}}^{\prime}, \Phi_{\mathrm{a}}^{\prime}, T^{\prime}$ and $P^{\prime}$ are the corresponding variables under standard conditions. This allows the instrument to be used in varying conditions, e.g., for airborne measurements (Mirme et al., 2010).

\subsection{Mathematical model}

The instrument response of the NAIS is a set of electric currents that are generated by the flux of ions precipitating to the analyzer sections. Each section current $y_{i}$ equals the sum of the charge flux of all aerosol particles of the size distribution $f(r)$ that reach the section $i$ :

$y_{i}=\int\left[e \sum_{q} q G(i, z) P(q, r)\right] f(r) \mathrm{d} r, \quad(i=1, \ldots, n)$,

where $G(i, z)$ is the response of analyzer section $i$ to unit concentration of singly charged ions with mobility $z$, and $P(q, r)$ is the probability that a particle with radius $r$ carries $q$ elementary charges $(e)$.

In the case of an ion analyzer (electric charge $q=1$ and charging probability function $P=1$ ), the response function $G$ is equal to the amount of airflow from which the ions of the given mobility are attached to the given analyzer section. In case of a particle analyzer, the charging probability $P(q, r)<1$ (Fig. 3) and size-equivalent mobility $z=z(q, r)$ functions are in effect.

The response function $G(i, z)$ for NAIS is presented in Fig. 5. The channels up to 12 are located quite densely on the mobility scale to provide higher mobility resolution in the cluster ion range (negative cluster ions $z \simeq 1.7 \mathrm{~cm}^{2} \mathrm{~V}^{-1} \mathrm{~s}^{-1}$, positive $z \simeq 1.3 \mathrm{~cm}^{2} \mathrm{~V}^{-1} \mathrm{~s}^{-1}$ ).

Despite the different peak values of different channels, the sum of the responses at any mobility is close to $\Phi_{\mathrm{a}}=500 \mathrm{~cm}^{3} \mathrm{~s}^{-1}$. Some decrease at higher mobilities is caused by particle loss at the inlet. The loss factor is arbitrary and is found during the calibration.

The system of Eq. (7) links the unknown aerosol distribution $f(r)$ with the measured currents $y_{i}(i=1, \ldots, n)$. 


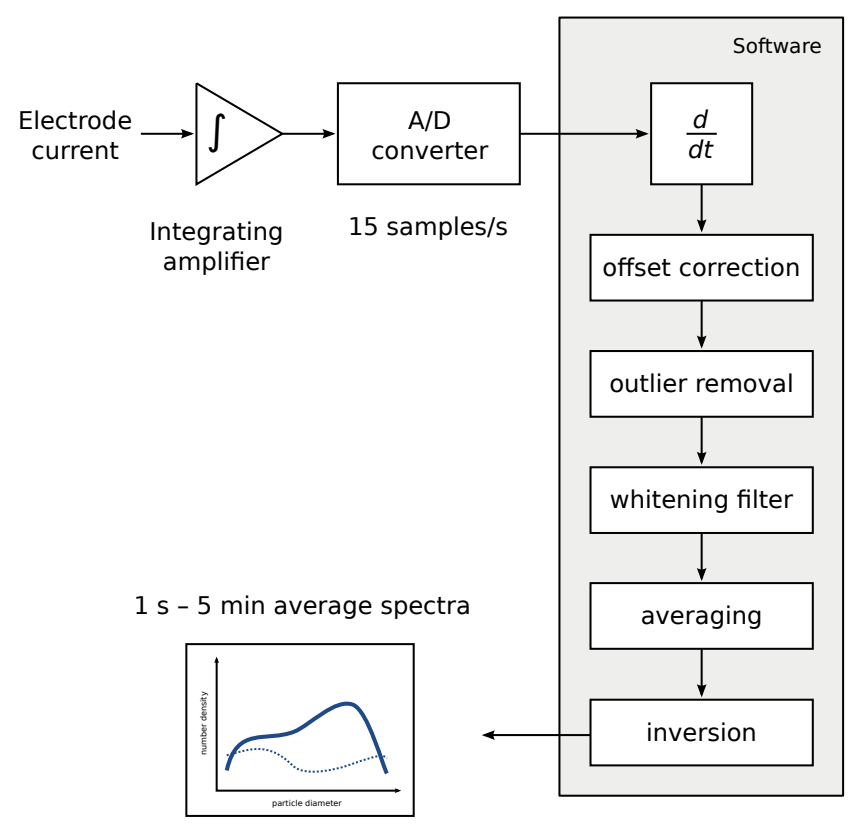

Fig. 6. Signal and data-processing flow diagram of the NAIS.

The equations should fully consider the instrument specificity (charging, mobility analysis, etc.).

\subsection{Electric current measurement}

The electric currents collected on the outer electrodes are very small: in the range of 1-3 fA per electrode in the cluster ion range and even smaller in the intermediate ion range (Hõrrak, 2001).

The NAIS uses integrating electrometric amplifiers where the fluxes of electric charge are collected on high-quality electrical capacitors. The output voltages of the amplifiers are proportional to the collected electric charge and the change of the voltage is proportional to incoming charge, i.e., to the aerosol current.

The integrating measurement principle allows for the best possible signal to noise ratio for electric current measurements. It is also well suited for the NAIS as the signal is collected continuously almost without any breaks - no signal is missed regardless of measurement frequency.

The NAIS uses a high measurement rate - each channel is measured 10 to 15 times per second). Several signal processing steps are used before reducing the signal to typically $10 \mathrm{~s}$ to 2 min average records (Fig. 6).

First the offset current and noise estimates are applied to the signal. The noise estimate described by variance is always processed together with the measured data through all the signal processing steps including the final data inversion; so that the resulting aerosol distributions will also have a noise level estimate.

Often short spikes occur in the electric current signal. These are probably caused by the random decay of

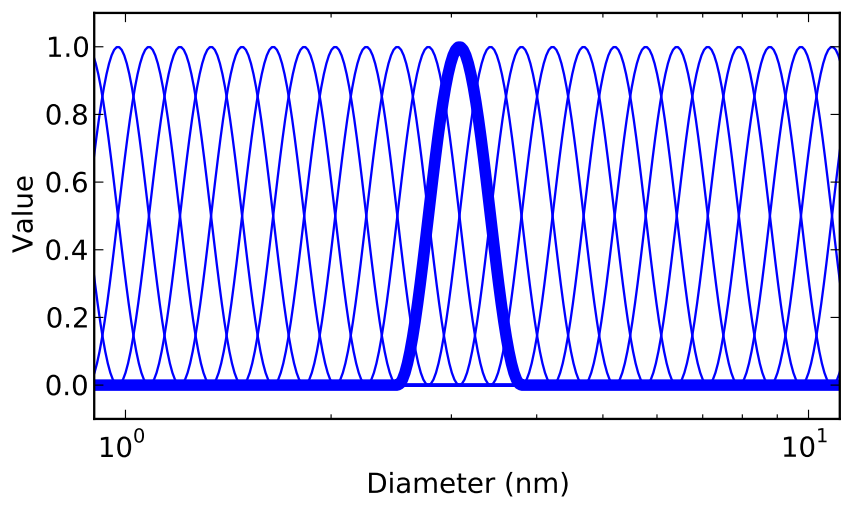

Fig. 7. Part of a typical set of elementary distributions used for NAIS with one distribution highlighted. Commonly, $\cos ^{2} x$ in the range $\left[-\frac{\pi}{2}, \frac{\pi}{2}\right]$ is used as the shape for the functions.

radioactive particles deposited on the electrodes. The frequency of spikes depends on the amount of debris that has collected on the electrodes. An outlier detection algorithm is used to discard the false signal measurements.

The excessively high measurement rate enables employment of optimal signal processing - an autoregressivemoving-average model (ARMA) is used. The electric current signal is passed through a matched digital filter to flatten the noise frequency distribution (noise whitening). This improves the effectiveness of averaging in case of short periods, i.e., $1-10 \mathrm{~s}$.

The collected charge on the capacitors needs to be cleared every once in a while. In a NAIS, the electrometers will automatically reset when the output signal reaches the upper or lower limit of the integrator. Signal from that electrometer is ignored for the duration of the reset and the settling, which takes about $10 \mathrm{~s}$. At low concentrations, resets can happen about once a day for each electrometer, which practically does not affect the measurements.

\section{Spectrum model}

The task of spectrometry is to solve the instrument response, Eq. (7), i.e., to find the aerosol distribution $f(r)$ from the measured channel currents.

The task is mathematically incorrect. An approximate solution is possible if we limit the information required for the description of the aerosol distribution. Therefore, we estimate the aerosol distribution as a sum of $m$ elementary distributions of predefined shapes $\phi^{j}(r)$ (Fig. 7):

$f(r)=\sum_{j} \phi_{j} \cdot \phi^{j}(r), \quad(j=1, \ldots, m)$.

The set is chosen based on the capabilities of the instrument and the data inversion. This way, an aerosol distribution is described by a set of coefficients $\phi_{j}$ (a spectrum) and the 
integral instrument response equations (Eq. 7) can be transformed into a set of linear equations (Eq. 9) or the equivalent matrix form (Eq. 10):

$$
\begin{aligned}
y_{i} & =\sum_{j} \mathbf{H}_{i j} \cdot \phi_{j}, \quad(i=1, \ldots, n), \\
\boldsymbol{y} & =\mathbf{H} \cdot \boldsymbol{\phi} .
\end{aligned}
$$

The instrument record vector $\boldsymbol{y}$ consists of section currents $y_{i}$ and the spectrum vector $\boldsymbol{\phi}$ consists of coefficients $\phi_{j}$. Matrix $\mathbf{H}$ can be called an apparatus matrix. The matrix element $\mathbf{H}_{i j}$ is the response of the analyzer section $i$ to the elementary aerosol distribution $\phi^{j}(r)$ (Eq. 11).

$\mathbf{H}_{i j}=\int\left[e \sum_{q} q G(i, z(q, r)) P(q, r)\right] \phi^{j}(r) \mathrm{d} r$

\subsection{Evaluation of the spectrum}

For the NAIS, the distribution is found by solving the apparatus equation (Eq. 10) in respect to spectrum $\boldsymbol{\phi}$. The inversion is performed with the Gauss-Markov method of least squares:

$\boldsymbol{\phi}=\left(\mathbf{H}^{T} \mathbf{D}^{-1} \mathbf{H}\right)^{-1} \mathbf{H}^{T} \mathbf{D}^{-1} \boldsymbol{y}$.

The measurement uncertainties are described by a covariance matrix $\mathbf{D}$, with the elements $D_{i i}=\Delta y_{i}^{2}$ being the variances of section currents. The uncertainty of the spectrum is then given by Eq. (13):

$\mathbf{W}=\left(\mathbf{H}^{T} \mathbf{D}^{-1} \mathbf{H}\right)^{-1}$.

The ordinary distribution can be estimated from spectrum $\phi$ with Eq. (8). Commonly, the distribution estimate is presented as a piecewise linear number density function.

\subsection{Regularization of the inversion}

In the case of the NAIS, the number of elementary distributions is larger than the number of electrometers. This means that the information matrix (Eq. 14) is always ill posed and it is not possible to invert it directly:

$\mathbf{V}=\mathbf{H}^{T} \mathbf{D}^{-1} \mathbf{H}$.

This is solved by using Tikhonov regularization (Tikhonov, 1963). The method allows increasing the rank of the matrix and thus correcting the ill-posedness (Lemmetty et al., 2005). The diagonal elements of $\mathbf{V}$ are amplified:

$\mathbf{V}_{i j}^{\prime}=\left\{\begin{array}{ll}\mathbf{V}_{i j} & \text { if } i \neq j, \\ \mathbf{V}_{i j} \cdot\left(1+\lambda_{i}\right) & \text { if } i=j\end{array}\right.$,

where $\lambda$ is an arbitrary regularization vector.
A quasi-optimal regularization is reached by performing a two-pass inversion. Initially, to make the inversion possible at all, the regularization parameter is set to a small constant: $\lambda_{i}=0.001$.

The second inversion is performed using a regularization vector based on uncertainty levels obtained from the first pass. The regularization vector $\lambda$ is calculated as the ratio of error $\mathbf{W}^{\prime}=\mathbf{V}^{\prime-1}$ to spectrum $\boldsymbol{\phi}$ :

$\lambda_{i}^{\prime}=K \cdot \frac{\mathbf{W}_{i i}^{\prime}}{\phi_{i}^{2}}$,

where $K$ is a constant in the range 0.1 to 1 . The values of $\lambda$ and $K$ are not critical and are chosen during the calibration of an instrument.

\subsection{Additional notes on inversion}

The inversion does not impose any constraints on the spectrum $\phi$, so negative values can appear in the solutions; for example, when the measured concentrations are very low. A simple procedure is used to remove these.

If negative values appear, the inversion is repeated with the assumption that the previously most negative element of $\phi$ is virtually zero and the corresponding column in the instrument matrix is dropped. Usually, two or three iterations are sufficient to remove all negative elements.

The procedure may increase the total concentration estimate. However, due to the nature of the inversion and significant overlapping of the elementary distributions, any correction of a spectrum element is balanced by changes in neighboring elements and the estimated spectrum still fits the measured currents. As a result, the effect remains below the level of measurement uncertainties.

Negative values in the inversion results may indicate that the number and shapes of the elementary distributions used to fit the spectrum do not match the actual measurement resolution of the instrument. Currently, evenly spaced elementary distributions with constant width in the logarithmic size or mobility scale are used (Fig. 7). The number of elementary distributions has been chosen so that the cluster ion peak would be correctly resolved. The size resolution of the instrument is lower for larger sizes (Fig. 5). This may cause diminished performance of the instrument in the size range above $15 \mathrm{~nm}$.

To confirm the inversion results a reverse-calculation procedure is used - the the solution distribution multiplied by the instrument matrix must match the original measured currents (Eq. 10). A mismatch would show that the resolution of the elementary distributions is too low or that the regularization is too strong.

In aerosol mode, particles larger than $20 \mathrm{~nm}$ will have a significant multiply charged fraction (Fig. 3). The instrument matrix naturally includes the response for the multiply charged particles. Correct inversion of the measured signal is only possible if both the multiply charged and singly charged 
fractions can be measured by the mobility analyzer. The data inversion can not account for the signal in the last measurement channels that is caused by the multiply charged fraction of particles beyond the upper size range $(\sim 40 \mathrm{~nm})$.

The presence of these larger particles in the aerosol sample will confuse the inversion. In practice, this means that particle concentration in the size range from $\sim 20 \mathrm{~nm}$ to $40 \mathrm{~nm}$ may be overestimated and the shape of the distribution may be distorted. In case of the NAIS it is not possible to use a cyclone to remove the larger particles in the inlet tract because this would cause high losses for the smallest measured particles. Further analysis and calibration is necessary to optimize the performance of the NAIS in this size range.

\section{Calibration methods}

The goal of the calibration is to find the best values for the instrument matrix elements $\mathbf{H}_{i j}$ (Eq. 11). General methods for the calibration of multichannel aerosol size spectrometers (Mirme, 1987; Tammet and Noppel, 1992) can be used for this. In principle, each one of the parallel channels in each of the different operating modes of the instrument requires calibration.

The calibration of NAIS is based on a mathematical model of the instrument. The instrument matrix is built by modeling electrometer currents for each particle size or mobility in a large set that covers densely the whole measurement range. The currents are combined to produce the instrument responses for the specified elementary distributions.

The instrument model is defined by a number of parameters. Most of these are "designed parameters" - they are fixed by the construction of the instrument (e.g., airflow rates, analyzer shape and voltages). A few parameters have to be found during the calibration of the instrument.

The analyzer transfer function $G(i, z)($ Eq. 7) is derived in a straightforward way and it is verified by calibration measurements in ions mode where the charging probability member is equal to one. Particle losses are estimated by fitting the diffusion length parameter of the instrument model to ion mode calibration results.

In the aerosol mode, additionally the charger and postfilter are activated and need to be taken into account: both $G(i, z)$ and $P(q, r)$ are in effect. $G(i, z)$ is already verified by the ion mode calibrations as the analyzer operates identically in all modes. Only the aerosol charging probability function $P(q, r)$ has to be calibrated.

The whole charge distribution for each of the modeled particle sizes is considered. It is assumed that initially particles have the steady state charge distribution, but is possible to calibrate for any charge distribution. The evolution of the whole charge distribution when particles pass the charger is carefully calculated.

Particle charging is both theoretically and technically poorly defined. So a preliminary calibration is made on a theoretical basis. Initially the parameters that define charging are given some estimated probable values. These are fine tuned during the calibration procedure when the measurement data is verified against well-defined laboratory aerosols (Mirme, 1987; Tammet and Noppel, 1992).

Producing correct calibration aerosols in the whole measurement range of NAIS is very difficult. The NAIS uses a mixed calibration based on a mathematical model of the instrument. The model parameters that are known or can be measured with high accuracy are fixed and only verified during calibration. These parameters include the analyzer geometry, electrode voltage (Table 1), airflow rates and electrometer sensitivity. From this, an approximate calibration is built, which is used to experimentally assess the remaining, poorly defined parameters, such as the particle loss factor of the inlet tract.

\section{Results and discussion}

In this paper we describe the second generation NAIS, which was developed with the primary motivation to enable the instrument to operate at varying altitudes on board an aircraft, but also to improve the reliability of regular measurements. The most important enhancements over the first generation are a new data acquisition system and an updated airflow scheme; the older instruments lack the automatic airflow adjustment, automatic charger/filter tuning and the signal processing steps that rely on a high measurement rate.

The calibration and verification of NAIS is a complex task. All the instruments have been briefly tested and calibrated at the facilities of University of Tartu (Mirme et al., 2007). Their performance has been more thoroughly studied in several calibration and intercomparison experiments at the University of Helsinki.

In 2008, five NAIS and five AIS instruments were compared and calibrated at the University of Helsinki using high resolution and Hauke-type DMAs for mobility references, and a CPC and an aerosol electrometer for concentration references (Asmi et al., 2009). The NAISs overestimated the size of negative ions by $20-52 \%$ and the size of positive ions by $24-54 \%$. The concentration measurements from NAISs were shown to be reliable at medium and high concentrations, but at lower concentrations the NAISs showed some background noise.

In 2010, six NAIS and five AIS instruments were evaluated at the University of Helsinki regarding particle size/mobility and concentration using mobility standards and silver particles covering the size range between 1 and $40 \mathrm{~nm}$ (Gagné et al., 2011). The instruments were compared to a differential mobility particle sizer (DMPS), a BSMA (Tammet, 2006) and an Ion-DMPS. The experiments showed that the mobility detection of the AIS and NAIS instruments is reliable, provided that the instrument is clean and the flows are not obstructed. That said, the NAIS can overestimate the 
concentration by a factor of $2-3$ in the particles measurement mode.

Nevertheless, the results should be regarded as quite good considering that the design goal of the AIS/NAIS was to provide researchers of atmospheric aerosol phenomena the most comprehensive information on the nucleation and aerosol formation processes, including electrical effects. In these studies, it is important that the instrument can reliably track the variations of the distributions and that it requires little maintenance. It should also be considered that features of specific comparison setups have a strong effect on comparison results: this includes the sample aerosol preparation, its electrical state, verification, and transport to the instrument.

Due to the different measurement modes and the particlesize/ion-mobility range of the instrument, already the proper preparation of verification aerosol is a challenging task. For example, almost all well-defined aerosols are produced using aerosol classifiers. That suits well for the NAIS if ion mode is verified. However, that is not very representative for particle mode because atmospheric aerosol is normally close to a steady state charge distribution. An additional neutralizer corrects the calibration aerosol but also adds a lot of ions generated by the neutralizer itself. These ions are detected and confuse the first measurement channels and thus need to be removed before entering the instrument.

An inherent problem for all instruments measuring neutral particles and using unipolar corona charging combined with electrical mobility analysis is that the charger ions have the same mobility as particles smaller than $2 \mathrm{~nm}$. This defines the lower limit of the measurement size range of the NAIS for neutral particles.

A feature of NAIS compared to scanning-type instruments is the great number of parallel channels. This ensures a fast and correct response to quickly varying aerosol, but has the drawback that a deviation of the geometry of a specific channel not accounted for in calibration may produce a deviation in output distribution.

The NAIS uses a relatively high sample flow rate $\left(54 \mathrm{~L} \mathrm{~s}^{-1}\right)$ to achieve a good sensitivity, high time resolution ( $1 \mathrm{~s}$ or better) and to keep losses of cluster ions low in the inlet tract.

The size/mobility resolution of NAIS is dependent on the signal to noise ratio. Higher noise causes stronger regularization in the data inversion and thus decreased resolution. The most commonly used inversion matrices produce 16 size fractions per decade for particle mode distributions and 8 mobility fractions per decade for ion mode distributions, i.e., 28 fractions for the whole measurement range in both operating modes.

On the whole, the limits of the instrument are outweighed by the high reliability, low maintenance requirements and ability to measure undisturbed in a varying environment at a high time resolution and wide size range.

There are more than 15 NAIS instruments in use today. The spectrometers have been measuring around the world in

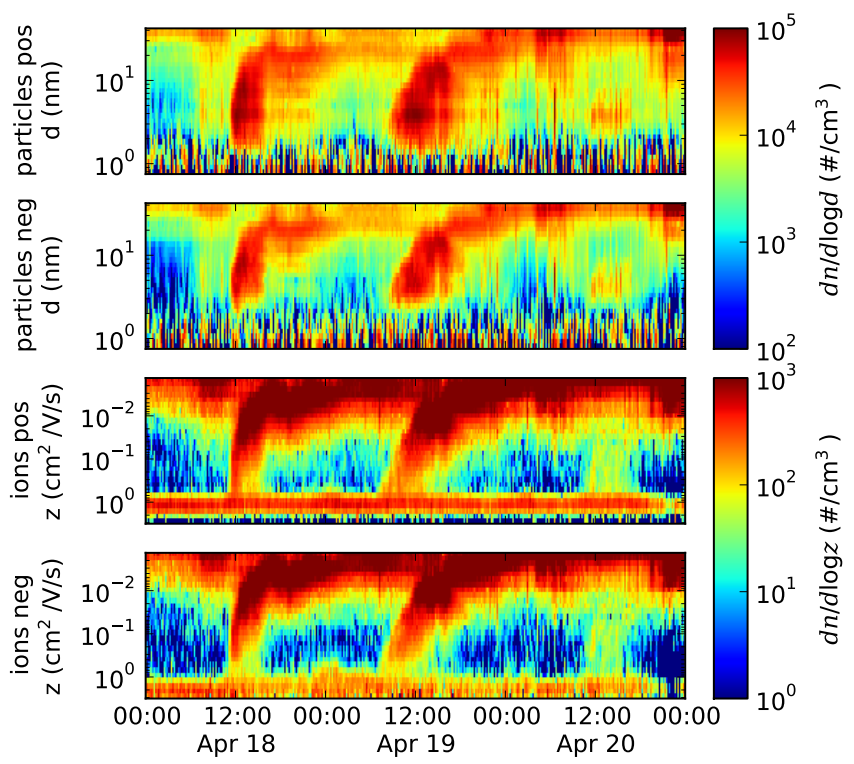

Fig. 8. Typical new particle formation events measured using the NAIS near the town center of Tartu, Estonia.

many different urban and rural environments, as well as on board an aircraft and a hot-air balloon (see Hirsikko et al., 2011 for references).

A number of NAIS and AIS instruments were used in the EUCAARI (European Integrated Project on Aerosol Cloud Climate Air Quality Interactions; Kulmala et al., 2009; Manninen et al., 2010; Kerminen et al., 2010) project measurement stations in 2008 and 2009. During the EUCAARI LONGREX (Long Range Experiment) airborne measurement campaign, the NAIS for the first time measured neutral sub- $3 \mathrm{~nm}$ particles in the free troposphere at altitudes of up to $8 \mathrm{~km}$ (Mirme et al., 2010).

\section{Conclusions}

In this article we have presented the principles of operation of an aerosol instrument - Neutral cluster and Air Ion Spectrometer (NAIS) - that can measure the distributions of ions in both polarities as well as uncharged particles. Ions are detected in the electric mobility range from 3.2 to $0.0013 \mathrm{~cm}^{2} \mathrm{~V}^{-1} \mathrm{~s}^{-1}$ and aerosol particles are detected in the size range from 2.0 to $40 \mathrm{~nm}$. The instrument measures the whole mobility range of both polarities of ions simultaneously. Alternatively, the instrument measures uncharged particles in the whole size range by using both positive and negative particle charging (Fig. 8). The parallel measurement principle allows the instrument to achieve time resolutions of up to $1 \mathrm{~s}$ depending on particle concentrations.

The NAIS has proven to be an invaluable instrument in studying atmospheric new particle formation. 
Acknowledgements. This research has been in part supported by the European Commission 6th Framework program projects: EUCAARI, contract no. 036833-2 (EUCAARI), by the Estonian Science Foundation through grants 8342 and 8417, and the Estonian Research Council Targeted Financing Project SF0180043s08.

Edited by: A. Wiedensohler

\section{References}

Asmi, E., Sipilä, M., Manninen, H. E., Vanhanen, J., Lehtipalo, K., Gagné, S., Neitola, K., Mirme, A., Mirme, S., Tamm, E., Uin, J., Komsaare, K., Attoui, M., and Kulmala, M.: Results of the first air ion spectrometer calibration and intercomparison workshop, Atmos. Chem. Phys., 9, 141-154, doi:10.5194/acp-9-141-2009, 2009.

Boisdron, T. and Brock, J. R.: On the stochastic nature of the acquisition of elecric charge and radioactivity by aerosol particles, Atmos. Environ., 4, 35-50, 1970.

Flagan, R. C.: History of Electrical Aerosol Measurements, Aerosol Sci. Technol., 28, 301-380, 1998.

Fuchs, N. A.: On the stationary charge distribution on aerosol particles in bipolar ionic atomosphere, Geofis. Pura Appl., 56, 185193, 1963.

Fuchs, N. A.: The Mechanics of Aerosols, Pergamon Press, Oxford, 1964.

Gagné, S., Lehtipalo, K., Manninen, H. E., Nieminen, T., Schobesberger, S., Franchin, A., Yli-Juuti, T., Boulon, J., Sonntag, A., Mirme, S., Mirme, A., Hõrrak, U., Petäjä, T., Asmi, E., and Kulmala, M.: Intercomparison of air ion spectrometers: an evaluation of results in varying conditions, Atmos. Meas. Tech., 4, 805-822, doi:10.5194/amt-4-805-2011, 2011.

Hirsikko, A., Nieminen, T., Gagné, S., Lehtipalo, K., Manninen, H. E., Ehn, M., Hõrrak, U., Kerminen, V.-M., Laakso, L., McMurry, P. H., Mirme, A., Mirme, S., Petäjä, T., Tammet, H., Vakkari, V., Vana, M., and Kulmala, M.: Atmospheric ions and nucleation: a review of observations, Atmos. Chem. Phys., 11, 767798, doi:10.5194/acp-11-767-2011, 2011.

Hõrrak, U.: Air ion mobility spectrum at a rural area, Ph.D. thesis, University of Tartu, 2001.

Hõrrak, U., Salm, J., and Tammet, H.: Statistical characterization of air ion mobility spectra at Tahkuse Observatory: Classification of air ions, J. Geophys. Res. Atmos., 105, 9291-9302, 2000.

Jiang, J. K., Chen, M. D., Kuang, C. A., Attoui, M., and McMurry, P. H.: Electrical Mobility Spectrometer Using a Diethylene Glycol Condensation Particle Counter for Measurement of Aerosol Size Distributions Down to $1 \mathrm{~nm}$, Aerosol Sci. Technol., 45, 510521, doi:10.1080/02786826.2010.547538, 2011a.

Jiang, J. K., Zhao, J., Chen, M. D., Eisele, F. L., Scheckman, J., Williams, B. J., Kuang, C. A., and McMurry, P. H.: First Measurements of Neutral Atmospheric Cluster and 1-2 nm Particle Number Size Distributions During Nucleation Events, Aerosol Science and Technology, 45, II-V, doi:10.1080/02786826.2010.546817, 2011b.

Kerminen, V.-M., Petäjä, T., Manninen, H. E., Paasonen, P., Nieminen, T., Sipilä, M., Junninen, H., Ehn, M., Gagné, S., Laakso, L., Riipinen, I., Vehkamäki, H., Kurten, T., Ortega, I. K., Dal Maso, M., Brus, D., Hyvärinen, A., Lihavainen, H., Leppä, J., Lehtinen, K. E. J., Mirme, A., Mirme, S., Hõrrak, U., Berndt,
T., Stratmann, F., Birmili, W., Wiedensohler, A., Metzger, A., Dommen, J., Baltensperger, U., Kiendler-Scharr, A., Mentel, T. F., Wildt, J., Winkler, P. M., Wagner, P. E., Petzold, A., Minikin, A., Plass-Dülmer, C., Pöschl, U., Laaksonen, A., and Kulmala, M.: Atmospheric nucleation: highlights of the EUCAARI project and future directions, Atmos. Chem. Phys., 10, 10829-10848, doi:10.5194/acp-10-10829-2010, 2010.

Kulmala, M., Vehkimäki, H., Petäjä, T., Maso, M., Lauri, A., Kerminen, V.-M., Birmili, W., and McMurry, P. H.: Formation and growth rates of ultrafine atmospheric particles: A review of observations, J. Aerosol Sci., 35, 143-176, 2004.

Kulmala, M., Mordas, G., Petäjä, T., Grönholm, T., Aalto, P., Vehkamäki, H., Hienola, A. I., Herrmann, E., Sipilä, M., Riipinen, I., Manninen, H., Hämeri, K., Stratmann, F., Bilde, M., Winkler, P. M., Birmili, W., and Wagner, P. E.: The Condensation Particle Counter Battery (CPCB): A New Tool to Investigate the Activation Properties of Nanoparticles, J. Aerosol Sci., 38, 289-304, 2007a.

Kulmala, M., Riipinen, I., Sipilä, M., Manninen, H. E., Petäjä, T., Junninen, H., Maso, M. D., Mordas, G., Mirme, A., Vana, M., Hirsikko, A., Laakso, L., Harrison, R. M., Hanson, I., Leung, C., Lehtinen, K. E., and Kerminen, V.-M.: Towards direct measurement of atmospheric nucleation, Science, 318, 89-92, $2007 \mathrm{~b}$.

Kulmala, M., Asmi, A., Lappalainen, H. K., Carslaw, K. S., Pöschl, U., Baltensperger, U., Hov, Ø., Brenquier, J.-L., Pandis, S. N., Facchini, M. C., Hansson, H.-C., Wiedensohler, A., and O'Dowd, C. D.: Introduction: European Integrated Project on Aerosol Cloud Climate and Air Quality interactions (EUCAARI) - integrating aerosol research from nano to global scales, Atmos. Chem. Phys., 9, 2825-2841, doi:10.5194/acp-9-2825-2009, 2009.

Kulmala, M., Petäjä, T., Nieminen, T., Sipilä, M., Manninen, H., Lehtipalo, K., Dal Maso, M., Aalto, P., Junninen, H., Paasonen, P., Riipinen, I., Lehtinen, K. E. J., Laaksonen, A., and Kerminen, V.-M.: Measurement of the nucleation of atmospheric aerosol particles, Nature Protocols, 7, 1651-1667, 2012.

Lehtipalo, K., Sipilä, M., Riipinen, I., Nieminen, T., and Kulmala, M.: Analysis of atmospheric neutral and charged molecular clusters in boreal forest using pulse-height CPC, Atmos. Chem. Phys., 9, 4177-4184, doi:10.5194/acp-9-4177-2009, 2009.

Lemmetty, M., Marjamäki, M., and Keskinen, J.: The ELPI response and data reduction II: Properties of kernel and data inversion, Aerosol Sci. Technol., 39, 583-595, 2005.

Manninen, H. E., Nieminen, T., Asmi, E., Gagné, S., Häkkinen, S., Lehtipalo, K., Aalto, P., Vana, M., Mirme, A., Mirme, S., Hõrrak, U., Plass-Dülmer, C., Stange, G., Kiss, G., Hoffer, A., Törõ, N., Moerman, M., Henzing, B., de Leeuw, G., Brinkenberg, M., Kouvarakis, G. N., Bougiatioti, A., Mihalopoulos, N., O'Dowd, C., Ceburnis, D., Arneth, A., Svenningsson, B., Swietlicki, E., Tarozzi, L., Decesari, S., Facchini, M. C., Birmili, W., Sonntag, A., Wiedensohler, A., Boulon, J., Sellegri, K., Laj, P., Gysel, M., Bukowiecki, N., Weingartner, E., Wehrle, G., Laaksonen, A., Hamed, A., Joutsensaari, J., Petäjä, T., Kerminen, V.-M., and Kulmala, M.: EUCAARI ion spectrometer measurements at 12 European sites - analysis of new particle formation events, Atmos. Chem. Phys., 10, 7907-7927, doi:10.5194/acp-10-79072010, 2010.

Manninen, H. E., Franchin, A., Schobesberger, S., Hirsikko, A., Hakala, J., Skromulis, A., Kangasluoma, J., Ehn, M., Junninen, 
H., Mirme, A., Mirme, S., Sipilä, M., Petäjä, T., Worsnop, D. R., and Kulmala, M.: Characterisation of corona-generated ions used in a Neutral cluster and Air Ion Spectrometer (NAIS), Atmos. Meas. Tech., 4, 2767-2776, doi:10.5194/amt-4-2767-2011, 2011.

Marti, J. J., Weber, R. J., Saros, M. T., Vasiliou, J. G., and McMurry, P. H.: Modification of the TSI 3025 condensation particle counter for pulse height analysis, Aerosol Sci. Technol., 25-2, 214-218, 1996.

Mirme, A.: About the calibration of the electrical aerosol spectrometer, Acta et comm. Univ. Tartuensis, 755, 71-79, 1987.

Mirme, A., Tamm, E., Mordas, G., Vana, M., Uin, J., Mirme, S., Bernotas, T., Laakso, L., Hirsikko, A., and Kulmala, M.: A wide range multi-channel Air Ion Spectrometer, Boreal Environ. Res., 12, 247-264, 2007.

Mirme, S., Mirme, A., Minikin, A., Petzold, A., Hõrrak, U., Kerminen, V. -M., and Kulmala, M.: Atmospheric sub-3 nm particles at high altitudes, Atmos. Chem. Phys., 10, 437-451, doi:10.5194/acp-10-437-2010, 2010.

Podolsky, A.: On the computation of the time of capturing ions by aerosol particle, Acta et comm. Univ. Tartuensis, 443, 62-73, 1977.

Salm, J.: Unipolar Charging of Initially Charged Aerosol, Acta et comm. Univ. Tartuensis, 947, 68-71, 1992.

Tammet, H.: The aspiration method for the Determination of Atmospheric-Ion Spectra, The Israel Program for Scientific Translations Jerusalem, National Science Foundation, Washington, DC, 1970.

Tammet, H.: On the techniques of aerosol electrical granulometry, Acta et comm. Univ. Tartuensis, 947, 94-115, 1992.

Tammet, H.: Size and mobility of nanometer particles, clusters and ions, J. Aerosol Sci., 26, 459-475, 1995.
Tammet, H.: Continuous scanning of the mobility and size distribution of charged clusters and nanometer particles in atmospheric air and the Balanced Scanning Mobility Analyzer BSMA, Atmos. Res., 82, 523-535, 2006.

Tammet, H. and Noppel, M.: Principles of the graduation of an electric aerosol granulometer, Acta et comm. Univ. Tartuensis, 947, 116-124, 1992.

Tammet, H., Mirme, A., and Tamm, E.: Electrical aerosol spectrometer of Tartu University, Atmos. Res., 62, 315-324, 2002.

Tikhonov, A. N.: Solution of incorrectly formulated problem and the regularization method, Soviet Math. Dokl, 4, 1035-1038, 1963.

Vanhanen, J., Mikkilä, J., Lehtipalo, K., Sipilä, M., Manninen, H., Siivola, E., Petäjä, T., and Kulmala, M.: Particle Size Magnifier for nano-CN detection, Aerosol Sci. Technol., 45, 533-542, doi:10.1080/02786826.2010.547889, 2011.

Wiedensohler, A., Birmili, W., Nowak, A., Sonntag, A., Weinhold, K., Merkel, M., Wehner, B., Tuch, T., Pfeifer, S., Fiebig, M., Fjäraa, A. M., Asmi, E., Sellegri, K., Depuy, R., Venzac, H., Villani, P., Laj, P., Aalto, P., Ogren, J. A., Swietlicki, E., Williams, P., Roldin, P., Quincey, P., Hüglin, C., Fierz-Schmidhauser, R., Gysel, M., Weingartner, E., Riccobono, F., Santos, S., Grüning, C., Faloon, K., Beddows, D., Harrison, R., Monahan, C., Jennings, S. G., O’Dowd, C. D., Marinoni, A., Horn, H.-G., Keck, L., Jiang, J., Scheckman, J., McMurry, P. H., Deng, Z., Zhao, C. S., Moerman, M., Henzing, B., de Leeuw, G., Löschau, G., and Bastian, S.: Mobility particle size spectrometers: harmonization of technical standards and data structure to facilitate high quality long-term observations of atmospheric particle number size distributions, Atmos. Meas. Tech., 5, 657-685, doi:10.5194/amt5-657-2012, 2012. 